\title{
Stress Distribution of CF/EP Laminated Composites under Supercritical Conditions
}

\author{
Haihong Huang, Zhenwen Li, Huanbo Cheng, and Yanzhen Yin \\ School of Mechanical \& Automotive Engineering, Hefei University of Technology, Hefei 230009, China \\ Correspondence should be addressed to Haihong Huang; huanghaihong@hfut.edu.cn
}

Received 6 October 2014; Accepted 19 January 2015

Academic Editor: Jose Ramon Leiza

Copyright (c) 2015 Haihong Huang et al. This is an open access article distributed under the Creative Commons Attribution License, which permits unrestricted use, distribution, and reproduction in any medium, provided the original work is properly cited.

\begin{abstract}
Enormous amounts of wastes have been produced due to extensive use of carbon fiber/epoxy resin (CF/EP) composites. The fact that the supercritical fluid can be used to recycle these composites efficiently has attracted widespread concerns. A threedimensional model of CF/EP laminates considering the interfacial layers was established. The internal stress distribution of laminates was simulated based on a heat transfer model; and the change of shear stress with supercritical temperature and pressure was investigated. The results show that the shear stress concentration was located in the interfacial layers; the maximum shear stress can be expressed by a curve of convex parabola to the temperature; and the most serious damage occurred in interfacial layers when temperature approached the glass-transition temperature of resin.
\end{abstract}

\section{Introduction}

Carbon fiber/epoxy resin (CF/EP) composites are used in a wide range of applications in industries such as aerospace, automotive and renewable energy, due to their interesting combination of properties, strength, durability, high strength-to-weight ratios, and resistance. The aircraft industry was an impressive example, with the Boeing 787 "Dreamliner" and Airbus A350 having up to 50\% of their weight in carbon fiber reinforced plastics (CFRP) [1]. And the structural parts commonly made of composite materials in automobiles include composite modular front end, tail doors, side doors, construction of body, chassis, interiors, and seating. The average CFRP weight content of a vehicle in Europe was around $24 \mathrm{~kg}$ [2]. However, their inherent heterogeneous nature of the matrix and reinforcement leads to the thorny problem of waste disposal. With the advancement of sustainable development strategy in the 21st century, many countries encourage and support clean production, thereby reducing discharge of solid wastes. The worldwide productivity of carbon fiber reached approximately 100,000 tons, while the sales amount reached 50,000 tons in 2013. The increasing use of CFRP also leads to an increasing amount of wastes. In 2010, the global waste carbon fiber products have reached 20,000 tons, while the recycle rate is merely $10 \%$. These wastes contained carbon fibers more than 10,000 tons [3]. It is urgent to explore and industrialize the recycle and reuse of the CF/EP wastes. CF/EP composites have accounted for more than $90 \%$ of CFRP based on the investigation [4]. Therefore, the environmental harmless recycle and reuse of $\mathrm{CF} / \mathrm{EP}$ composites have great environmental significance and economic value.

Three technologies have been proposed to recycle CF/EP composites: mechanical recycling, thermal processing, and chemical recycling [5]. Chemical recycling has been investigated using supercritical fluids as a reactive-extraction media, since they possess an interesting combination of properties such as low viscosity, high mass transport coefficients, high diffusivity, and salvation power [6]. The University of Nottingham developed a supercritical solvent decomposition method, and the recycled carbon fiber retained its original strength (up to $98 \%$ ) $[7,8]$. When the potassium hydroxide $(\mathrm{KOH})$ was used as catalyst, yield of resin elimination reached $95 \%$. Okajima et al. studied the decomposition of epoxy resin in the near-critical and supercritical water, in which $380^{\circ} \mathrm{C}$ and $25 \mathrm{MPa}$ were determined preliminarily to be the optimal 


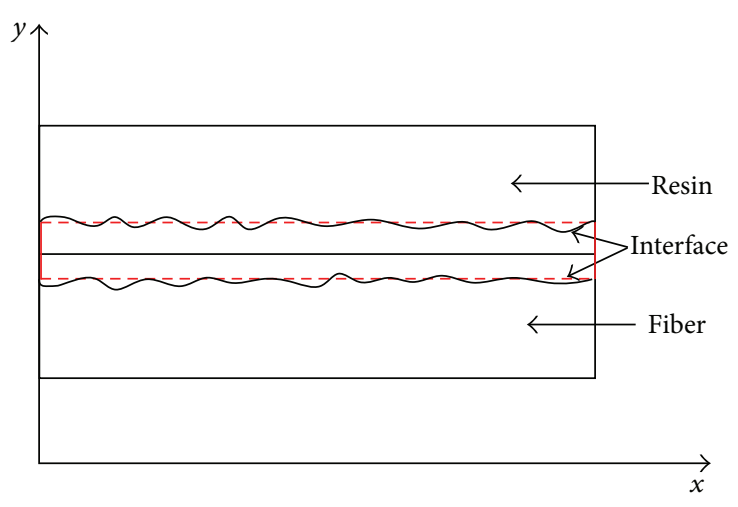

(a)

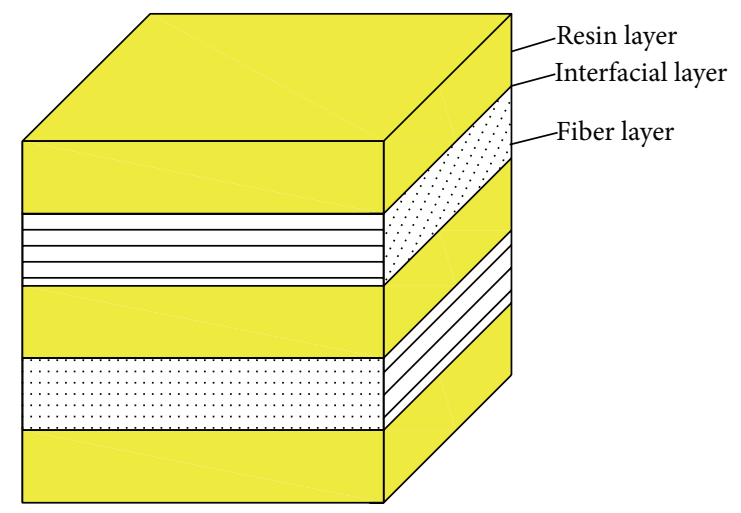

(b)

Figure 1: (a) Representative volume element (RVE); (b) equivalent model of laminates.

processing conditions [9]. Liu et al. found that supercritical water was a realistic option for the depolymerisation of epoxy resin and its composites [10].

Finite element method (FEM) has been proved to be feasible and effective to simulate the stress field distribution of composites. Lu et al. acquired thermal-stress distribution of CFRP during thermal cycling using micromechanical finite element model [11]. Gao et al. carried out numerical simulation of internal thermal stress of unidirectional CF/EP composites using two-dimensional finite element model and found that internal thermal stress of the interfacial region was obviously concentrated [12]. Li et al. simulated the stress distribution for printed circuit board (PCB) in the supercritical $\mathrm{CO}_{2}$ environment and found that the internal delamination was determined by shear stress and peel stress [13]. However, the stress distribution of CF/EP composites under supercritical conditions has not been studied in the context of recycling.

This paper selects CF/EP laminated composites as the research object. An equivalent three-dimensional model was established, and the model of heat transfer was proposed under supercritical condition. Thermal-stress coupling analysis was completed based on FEM, in which the supercritical fluid temperature and pressure were set as the boundary conditions of load. The internal stress distribution of laminates was analyzed. With changes of supercritical environment, that is, temperature and pressure, the variation of maximum shear stress was studied. The advantage of this simulation is that it is possible to identify the impact of different supercritical conditions on structural failure of composites, which provides useful guidelines for designing the recycling process of CF/EP composites.

\section{Equivalent Model and Heat Transfer Process Of CF/EP Laminates}

The equivalent three-dimensional model considering the interfacial layers is the key for the finite element simulation. Traditional modeling holds that the two layers of CF/EP laminates are connected by resin matrix, and the interlaminar properties depend largely on properties of matrix. However, the existence of interface between fiber and resin is neglected. Interface is a very important microcosmic structure, which not only connects fiber and matrix but also transfers loads from matrix to fiber. So it is very crucial to consider the existence of the interface. Interface is not a single geometric surface between reinforcement and matrix but the transitional region from matrix surface to reinforcement surface. According to the hybrid model, a single fiber is selected as a basic cell, called representative volume element (RVE), as shown in Figure 1(a) [14]. Based on the assumption that the transitional region is equivalent to the interface layer, an equivalent three-dimensional model of CF/EP laminates was established. The simplified laminates model was symmetric, which was laid by resin layer, interfacial layer, and fiber layer in turn. Equivalent three-dimensional model of CF/EP laminates was shown in Figure 1(b).

Heat transfer model of a lamina was shown in Figure 2(a). It was assumed that the size of lamina is infinite along $x$ direction. According to Fourier laws of heat conduction, the heat flux of laminate $Q_{1}$ can be calculated by (1) [15]. Consider

$$
Q_{1}=-k A \frac{d t}{d x}=-k A \frac{t_{2}-t_{1}}{l}=\frac{t_{1}-t_{2}}{(l / k A)},
$$

where $l$ is the single layer thickness of CF/EP, $k$ is the thermal conductivity, $A$ is the heat transfer area, $t_{1}$ and $t_{2}$ are the surface temperature, respectively, and $l \cdot k^{-1} \cdot A^{-1}$ is the thermal resistance.

The heat flux of laminates with different thickness and physical properties was calculated. The size and thermophysical properties of laminates were shown in Figure 2(b). The heat was transferred from the left to right in the model. Based on the series connection of thermal resistance, the heat flux of laminates $Q_{2}$ can be calculated by

$$
Q_{2}=\frac{t_{1}-t_{n}}{\sum_{i=1}^{n} l_{i} / k_{i} A},
$$

where $n$ is the layer number of laminates and $t_{1}$ and $t_{n}$ are the surface temperature for two sides of laminates. 


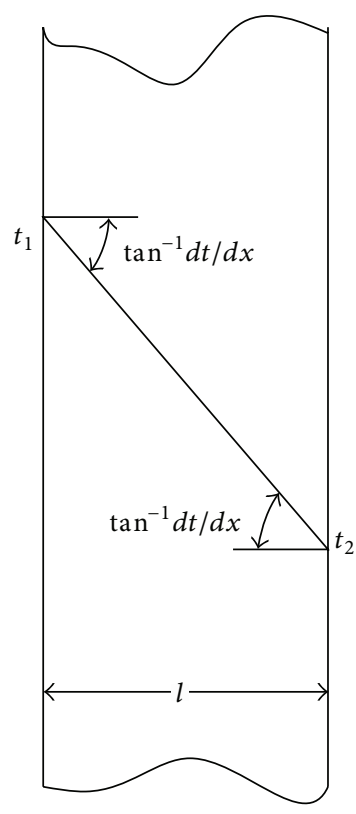

(a)

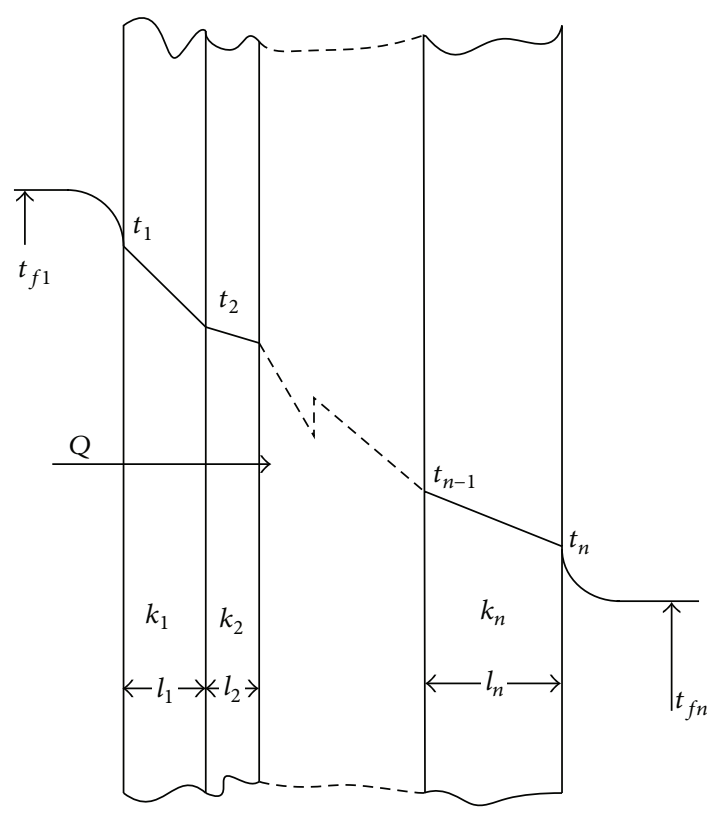

(b)

FIGURE 2: (a) Steady-state conduction of a lamina; (b) steady-state conduction of laminates.

TABLE 1: The property of CF/EP laminates at room temperature.

\begin{tabular}{lccc}
\hline Parameter & Fiber layer & Resin layer & Interfacial layer \\
\hline Thickness $(\mathrm{mm})$ & 0.15 & 0.15 & 0.001 \\
Density $\left(\mathrm{kg} / \mathrm{m}^{3}\right)$ & 1600 & 1200 & 1450 \\
Thermal conduction coefficient $\left(\mathrm{W} /\left(\mathrm{m} \cdot{ }^{\circ} \mathrm{C}\right)\right)$ & $k_{1}=4.6, k_{2}=k_{3}=0.42$ & 0.2 & 2.4 \\
Thermal expansion coefficient $\left(/{ }^{\circ} \mathrm{C}\right)$ & $\alpha_{1}=-1 \times 10^{-6}, \alpha_{2}=26 \times 10^{-6}$ & $60 \times 10^{-6}$ & $27 \times 10^{-6}$ \\
Poisson ratio & $v_{12}=0.28, v_{23}=0.4$ & 0.35 & 0.315 \\
Elastic modulus $(\mathrm{MPa})$ & $E_{1}=138 \times 10^{3}, E_{2}=E_{3}=11 \times 10^{3}$ & $4 \times 10^{3}$ & $7.5 \times 10^{3}$ \\
Specific heat $\left(\mathrm{J} /\left(\mathrm{g} \cdot{ }^{\circ} \mathrm{C}\right)\right)$ & 0.48 & 1.2 & 0.84 \\
\hline
\end{tabular}

Supercritical fluid was closed to the surfaces of laminates under supercritical conditions. In this case, thermal resistance of supercritical fluid should be taken in consideration. So the heat flux of laminates $Q_{3}$ can be calculated by the following:

$$
Q_{3}=\frac{t_{f 1}-t_{f n}}{1 / h_{1} A+\sum_{i=1}^{n} l_{i} / k_{i} A+1 / h_{n} A},
$$

where $t_{f 1}$ and $t_{f n}$ are the supercritical fluid temperature for the two sides of laminates and $h_{1}$ and $h_{n}$ are the surface convective heat transfer coefficient.

\section{Thermal-Stress Coupling Analysis}

Thermal-stress coupling analysis of the CF/EP laminates under supercritical conditions was simulated by ABAQUS. Temperature was calculated by transient thermal analysis to obtain the node temperature distribution firstly. And then, taking temperature field as thermal loads, the stress was calculated by structural analysis. The simulation was executed based on the following assumptions: (1) the change of convective heat transfer coefficient along with temperature and pressure was ignored; namely, the surface convective heat transfer coefficient was constant; (2) the reversecoupling effect of deformation process to temperature field was ignored; namely, the process was regarded as one-way sequentially coupled analysis.

3.1. Finite Element Model. The laminates model with size of $30 \mathrm{~mm} \times 30 \mathrm{~mm} \times 1.66 \mathrm{~mm}$ was established. As shown in Figure 3, it consisted of five fiber layers, six resin layers, and ten interfacial layers. The stacking sequence of fiber layers was $[0 / 90 / 0 / 90 / 0]$. To simplify calculation, $1 / 4$ of CF/EP laminated composites was analyzed due to its symmetry. Resin layers and interface layers were considered as isotropic homogeneous material, and fiber layers were considered as transversely isotropic material. Physical parameters of resin layers and fiber layers were given by reference [16], and parameters of the interfacial layers were given based on the rule of the general simple mixture [17], as shown in Table 1. The convective heat transfer coefficient of supercritical fluid was $4000 \mathrm{~W} /\left(\mathrm{m}^{2} \cdot{ }^{\circ} \mathrm{C}\right)$. 


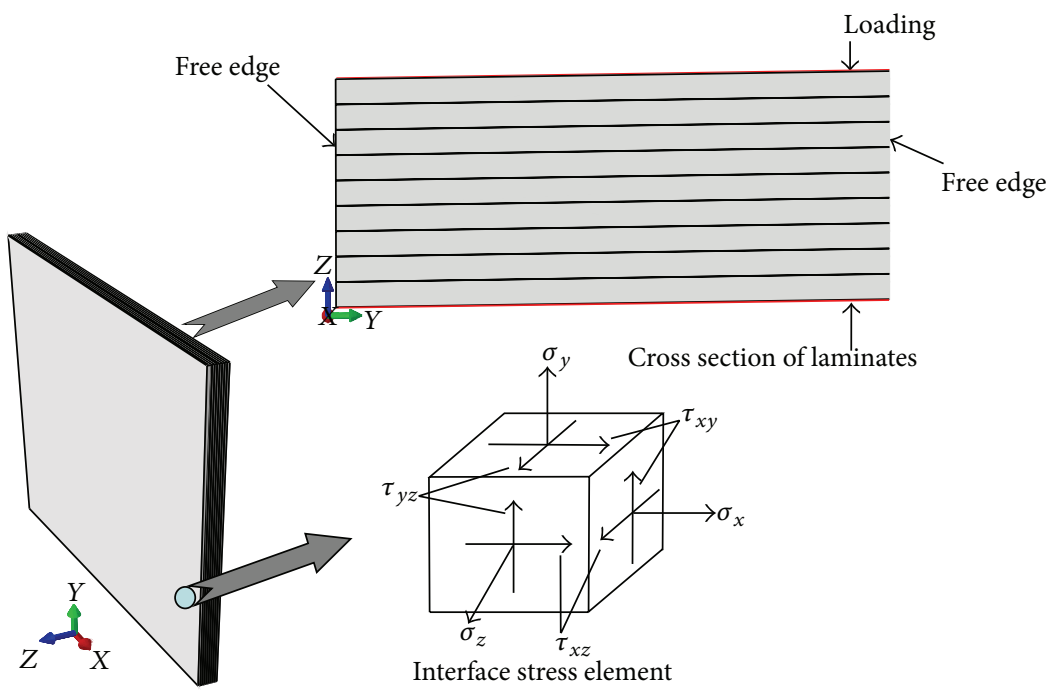

Figure 3: Model of CF/EP laminates and interface stress element.
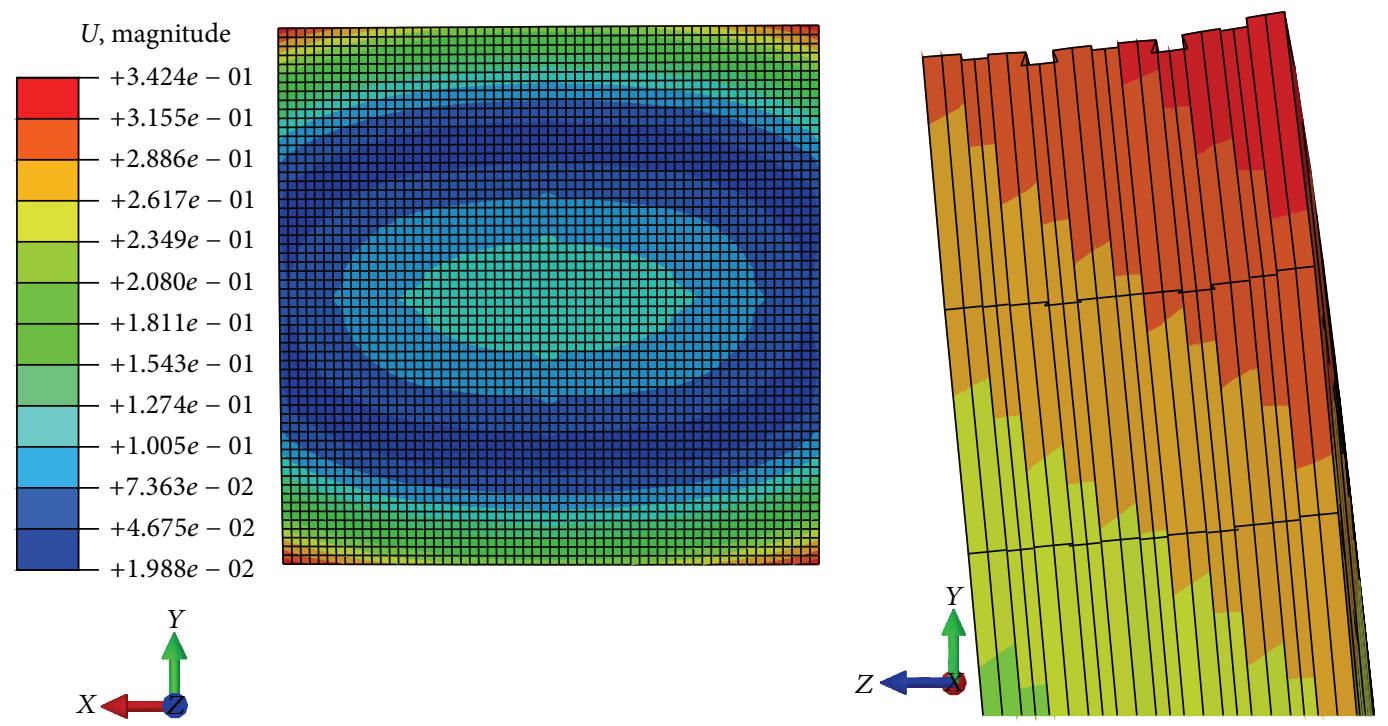

(a)

(b)

Figure 4: (a) Displacement distribution pattern of laminates at $300^{\circ} \mathrm{C}, 20 \mathrm{MPa}$; (b) displacement distribution pattern of local laminates at $300^{\circ} \mathrm{C}, 20 \mathrm{MPa}$.

3.2. Analysis of Simulation Results. As shown in Figure 4(a), the deformation of CF/EP laminates appeared under the thermal load, and the maximum displacement was more than two times the thickness of laminates at four corners. The thermal expansion coefficient of resin layer was far more than that of fiber layer along the length of fibers. Owing to the mismatch of thermal expansion coefficient, significantly interfacial slip deformation appeared, as shown in Figure 4(b).

The shear stress $\tau_{x z}, \tau_{y z}$ and peel stress $\sigma_{z}$ were caused by interfacial slip and mainly contributed to the interfacial failure of laminates. When the temperature of supercritical environment was set as $300^{\circ} \mathrm{C}$, the compressive stress increased significantly with the increase of pressure, but both shear stresses $\tau_{x z}$ and $\tau_{y z}$ had little change, as shown in Figure 5(a). Due to the compressive stress acting in the opposite direction of peel stress $\sigma_{z}$, the delamination of $\mathrm{CF} / \mathrm{EP}$ laminates was restrained gradually. When the pressure of supercritical environment was set as $10 \mathrm{MPa}$, both shear stresses $\tau_{x z}$ and $\tau_{y z}$ increased significantly with the increase of temperature, as shown in Figure 5(b). The shear stress $\tau_{y z}$ increased from $2.9 \mathrm{MPa}$ to $14.7 \mathrm{MPa}$ when the temperature goes from $50^{\circ} \mathrm{C}$ to $325^{\circ} \mathrm{C}$.

The shear stress became the main resource to result in structural damage of laminates, due to the fact that the peel stress manifested as compressive stress in supercritical conditions. As shown in Figure 6, the shear stress concentrated mainly on the interfacial layers, especially near the free edge, 


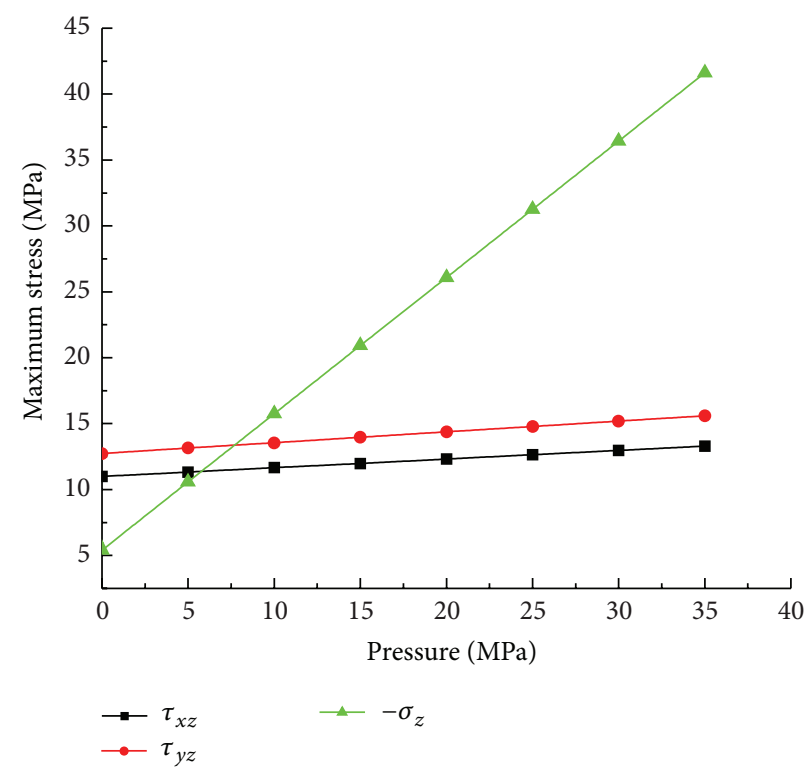

(a)

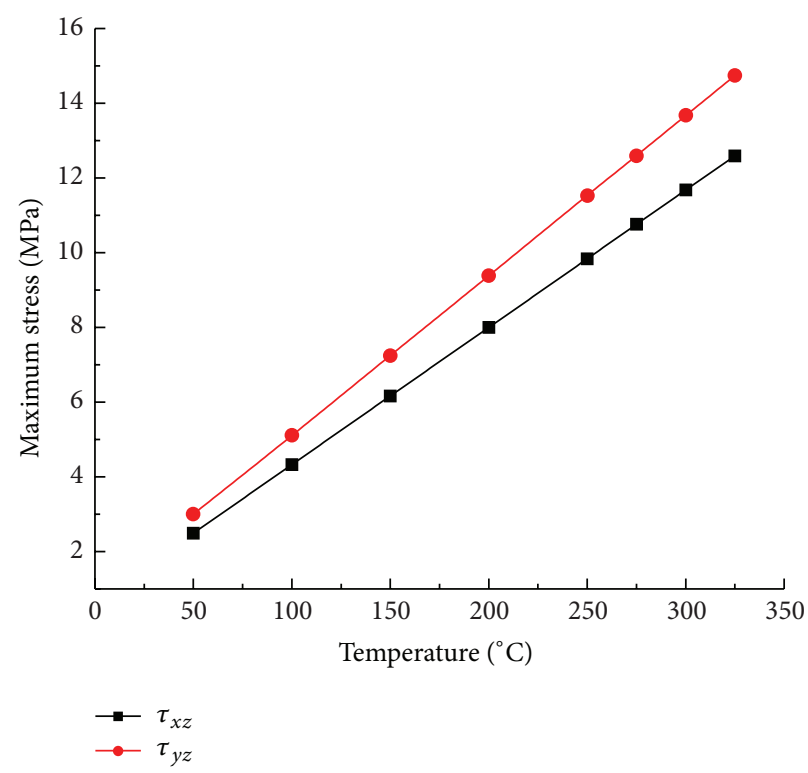

(b)

Figure 5: The impact of (a) pressure on the maximum shear/peel stress; and (b) temperature on the maximum shear stress.

TABLE 2: Elastic modulus and Poisson ratio of laminates at different temperature.

\begin{tabular}{lcccccccc}
\hline Temperature $\left({ }^{\circ} \mathrm{C}\right)$ & 50 & 100 & 150 & 200 & 250 & 275 & 300 & 325 \\
\hline Elastic modulus $(\mathrm{MPa})$ & $3.97 \times 10^{3}$ & $3.5 \times 10^{3}$ & $3.1 \times 10^{3}$ & $2.6 \times 10^{3}$ & $1.8 \times 10^{3}$ & $1.3 \times 10^{3}$ & $0.5 \times 10^{3}$ & $0.07 \times 10^{3}$ \\
Poisson ratio & 0.353 & 0.362 & 0.384 & 0.4 & 0.421 & 0.43 & 0.442 & 0.453 \\
\hline
\end{tabular}

and the stress decreased rapidly from the free edge to the inside. At either side of $0^{\circ}$ plies, shear stresses $\tau_{x z}$ were concentrated on the free edge of interfacial layer and their directions were opposite; and it was the same situation for the shear stresses $\tau_{y z}$ at either side of $90^{\circ}$ plies.

3.3. Discussion. Under the supercritical environment, the mechanical properties of resin were changed by the combined effect of supercritical fluid and temperature, while the effects of pressure can be neglected since there was little change of composite properties when increasing the pressure. In addition, the Elastic modulus of resin had considerable effect on the stress. The Elastic modulus of epoxy resin plummeted about 2-3 orders of magnitude, when it transformed from glassy state to rubbery state with the increase of temperature [18]. Although the glass-transition temperature of epoxy resin was affected by the composition, curing agent, and crosslinking degree, it was about $200^{\circ} \mathrm{C}$ when the crosslinking degree was $70 \%-90 \%$ based on the published researches [1923]. The Elastic modulus and Poisson ratio of laminates in different temperatures were shown in Table 2.

The shear stress of laminates under different supercritical conditions was calculated when the pressure of supercritical environment was set as $10 \mathrm{MPa}$, as shown in Figure 7. The change of Elastic modulus and Poisson ratio with the temperature was taken into consideration in the calculation. It showed that the maximum shear stress can be expressed by a curve of convex parabola to the temperature, and the peak of shear stress appeared at $250^{\circ} \mathrm{C}$. With the increase of supercritical fluid temperature, the maximum shear stress increased gradually at first and then decreased rapidly when the temperature was higher than the glass-transition temperature. The interfacial shear stress concentration was weakened due to the reduction of Elastic modulus.

3.4. The Recycling of CF/EP Laminates. The simulation verifies that the CF/EP laminates can be recycled by the supercritical fluids. Under the supercritical conditions, the supercritical fluid infiltrates into laminates through initial pores, which leads to the swelling behavior of resin; and the shear stress concentration appeared because of the slip deformation. When the shear force was greater than bonding force, the bonding interface among layers would be damaged. Supercritical fluid flowed rapidly through the new channels, which not only accelerated transmission of heat but also widened the extraction channel of reaction products. Consequently, the structural and interfacial bonding damaged more seriously. However, the interfacial shear stress decreased rapidly with the decrease of Elastic modulus when the temperature was higher than glass-transition temperature, 


$$
\begin{aligned}
& \text { S, } S_{13} \\
& \text { (Avg: } 75 \%)
\end{aligned}
$$
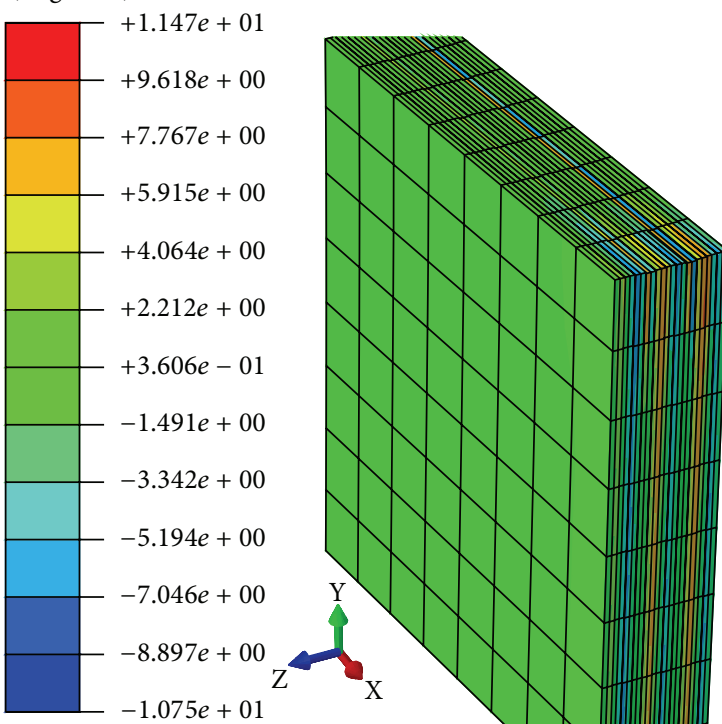

(a)

$S, S_{23}$ (Avg: $75 \%$ )
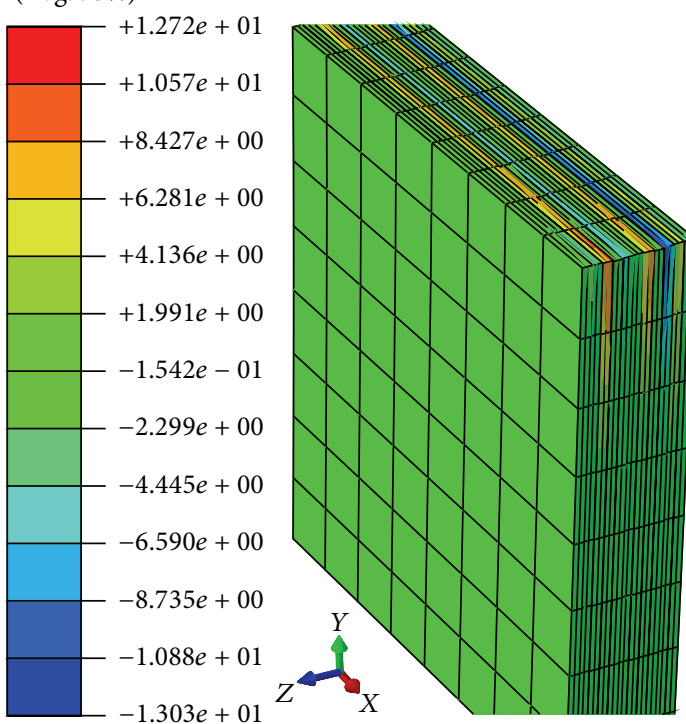

(c)
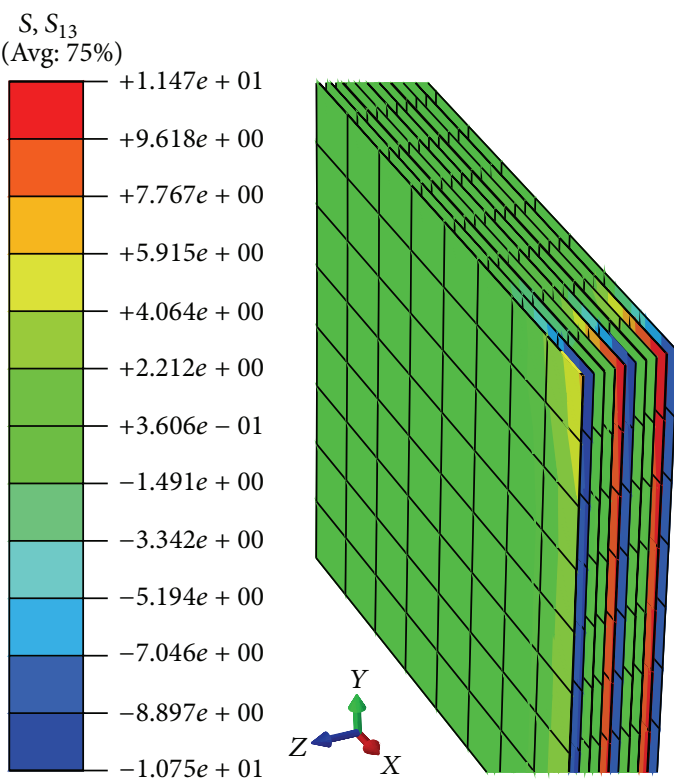

(b)

$S, S_{23}$

(Avg: $75 \%)$
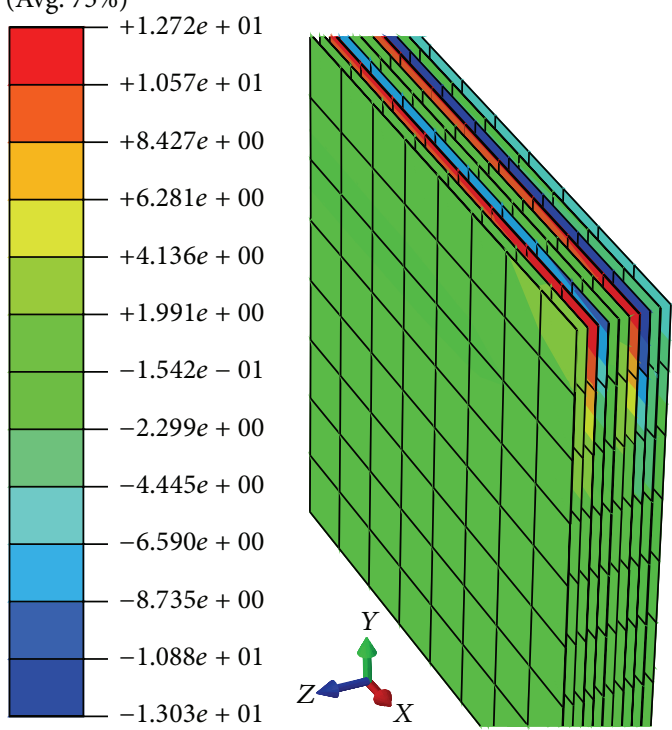

(d)

FIGURE 6: (a) Shear stress $\tau_{x z}$ of local laminates; (b) shear stress $\tau_{x z}$ of local interfacial layer; (c) shear stress $\tau_{y z}$ of local laminates; and (d) shear stress $\tau_{y z}$ of local interfacial layer.

which would make the recycling of composites inefficient. Therefore, the recycling process of CF/EP laminates should be operated near the glass-transition temperature of the resin.

\section{Conclusions}

The internal stress distribution of laminates was simulated by FEM under supercritical conditions. The results show that the interfacial slip deformation appeared due to the mismatch of thermal expansion coefficient between resin and fiber. The shear stress concentrated on the interfacial layer near the free edge, and the maximum shear stress can be expressed by a convex parabola to the temperature. The microstructure was damaged more seriously near glass-transition temperature, and the recycling processes of CF/EP laminates under the supercritical conditions were proposed. This stress distribution was simulated only under the condition of physical environment, that is, temperature and pressure, without considering the chemical decomposition effects of supercritical fluids. The presented model and simulations were suitable 


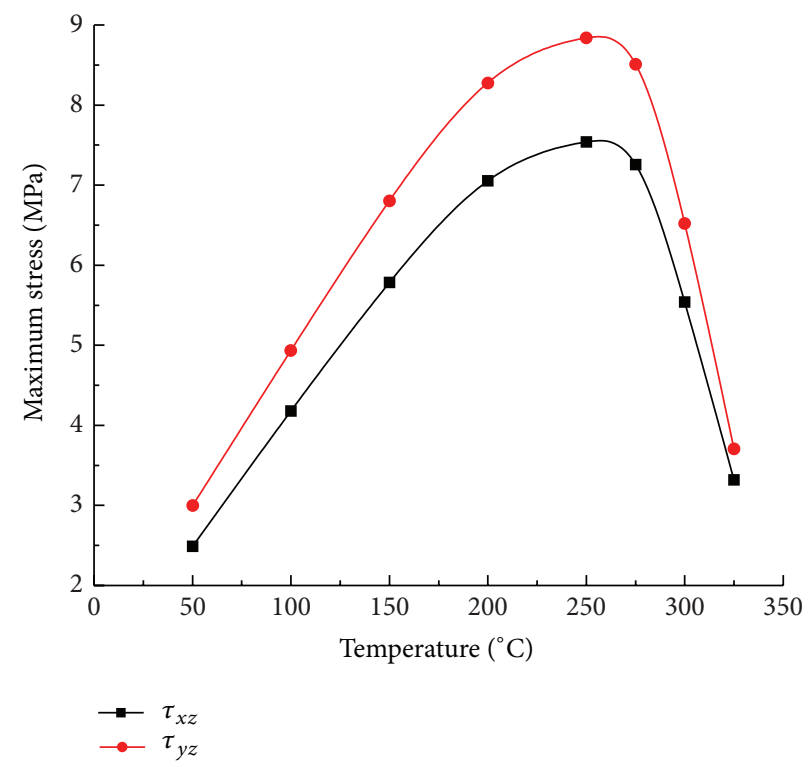

FIGURE 7: The variation of maximum shear stress when considering the change of Elastic modulus and Poisson ratio with temperature.

for the solvents such as water, alcohols, and acetone under supercritical conditions.

\section{Conflict of Interests}

The authors declare that there is no conflict of interests regarding the publication of this paper.

\section{Acknowledgments}

This work is financially supported by the National Natural Science Foundation of China (51375135) and Program for New Century Excellent Talents in University of Ministry of Education of China (NCET-12-0837).

\section{References}

[1] W. Carberry, "Aerospace's role in the development of the recycled carbon fibre supply chain," in Proceedings of the Carbon Fibre Recycling and Reuse Conference, Intertechpria, Hamburg, Germany, 2009.

[2] G. Belingardi and J. Obradovic, "Recent development in car body lightweight design: a contribution toward greener envrionment," Mobility \& Vehicle Mechanics, vol. 38, no. 4, pp. 7-23, 2012.

[3] C. E. Kouparitsas, C. N. Kartalis, P. C. Varelidis, C. J. Tsenoglou, and C. D. Papaspyrides, "Recycling of the fibrous fraction of reinforced thermoset composites," Polymer Composites, vol. 23, no. 4, pp. 682-689, 2002.

[4] S. Pimenta and S. T. Pinho, "Recycling carbon fibre reinforced polymers for structural applications: technology review and market outlook," Waste Management, vol. 31, no. 2, pp. 378-392, 2011.

[5] Y. X. Yang, R. Boom, B. Irion, D.-J. van Heerden, P. Kuiper, and H. de Wit, "Recycling of composite materials," Chemical
Engineering and Processing: Process Intensification, vol. 51, pp. 53-68, 2012.

[6] Z. F. Liu, W. S. Zhang, and H. C. Zhang, "Analysis of layered experiments on printed circuit board in the environment with supercritical $\mathrm{CO}_{2}$ fluid," Chinese Journal of Environmental Engineering, vol. 7, no. 5, 2011.

[7] G. Marsh, "Carbon recycling: a soluble problem," Reinforced Plastics, vol. 53, no. 5, pp. 22-27, 2009.

[8] R. Piñero-Hernanz, J. García-Serna, C. Dodds et al., "Chemical recycling of carbon fibre composites using alcohols under subcritical and supercritical conditions," The Journal of Supercritical Fluids, vol. 46, no. 1, pp. 83-92, 2008.

[9] I. Okajima, K. Yamada, T. Sugeta, and T. Sako, "Decomposition of epoxy resin and recycling of CFRP with sub- and supercritical water," Kagaku Kogaku Ronbunshu, vol. 28, no. 5, pp. 553-558, 2002.

[10] Y. Y. Liu, L. H. Meng, Y. D. Huang, and J. Du, "Recycling of carbon/epoxy composites," Journal of Applied Polymer Science, vol. 94, no. 5, pp. 1912-1916, 2004.

[11] C. Lu, P. Chen, and Y. Gao, "Thermal stress distribution in $\mathrm{CF} / \mathrm{EP}$ composite in low earth orbit," Journal of Composite Materials, vol. 44, no. 14, pp. 1729-1738, 2010.

[12] Y. Gao, X. J. Dai, S. L. Dong, C. Lu, and J. Bao, "Investigation of thermal stress in a unidirectional carbon fiber/epoxy resin composite under thermal cycling," Polymeric Materials Science and Engineering, vol. 28, no. 9, pp. 178-181, 2012.

[13] X. Y. Li, Z. F. Liu, and G. F. Liu, "Model analysis of printed circuit board's varying element in supercritical carbon dioxide," Modern Manufacturing Engineering, vol. 8, pp. 1-5, 2007.

[14] J. K. Kim and Y. M. Mai, Engineered Interfaces in Fiber Reinforced Composites, Elsevier, Amsterdam, The Netherlands, 1998.

[15] E. R. G. Eckert and R. M. Drake, Analysis of Heat and Mass Transfer, McGraw-Hill, New York, NY, USA, 1972.

[16] P. D. Soden, M. J. Hinton, and A. S. Kaddour, "Lamina properties, lay-up configurations and loading conditions for a range of fibre-reinforced composite laminates," Composites Science and Technology, vol. 58, no. 7, pp. 1011-1022, 1998. 
[17] R. F. Landel and L. E. Nielsen, Mechanical Properties of Polymers and Composites, Marcel Dekker, New York, NY, USA, 1993.

[18] O. Sindt, J. Perez, and J. F. Gerard, "Molecular architecturemechanical behaviour relationships in epoxy networks," Polymer, vol. 37, no. 14, pp. 2989-2997, 1996.

[19] D. R. Xin, Mechanical properties and the interface failure mechanism of epoxy resin under hygrothermal condition [Ph.D. thesis], South China University of Technology, Guangdong Province, China, 2013.

[20] C. Li and A. Strachan, "Molecular dynamics predictions of thermal and mechanical properties of thermoset polymer EPON862/DETDA," Polymer, vol. 52, no. 13, pp. 2920-2928, 2011.

[21] N. B. Shenogina, M. Tsige, S. S. Patnaik, and S. M. Mukhopadhyay, "Molecular modeling approach to prediction of thermomechanical behavior of thermoset polymer networks," Macromolecules, vol. 45, no. 12, pp. 5307-5315, 2012.

[22] J. C. Moller, S. A. Barr, E. J. Schultz, T. D. Breitzman, and R. J. Berry, "Simulation of fracture nucleation in cross-linked polymer networks," JOM, vol. 65, no. 2, pp. 147-167, 2013.

[23] L. Shen, L. Wang, T. Liu, and C. He, "Nanoindentation and morphological studies of epoxy nanocomposites," Macromolecular Materials and Engineering, vol. 291, no. 11, pp. 1358-1366, 2006. 

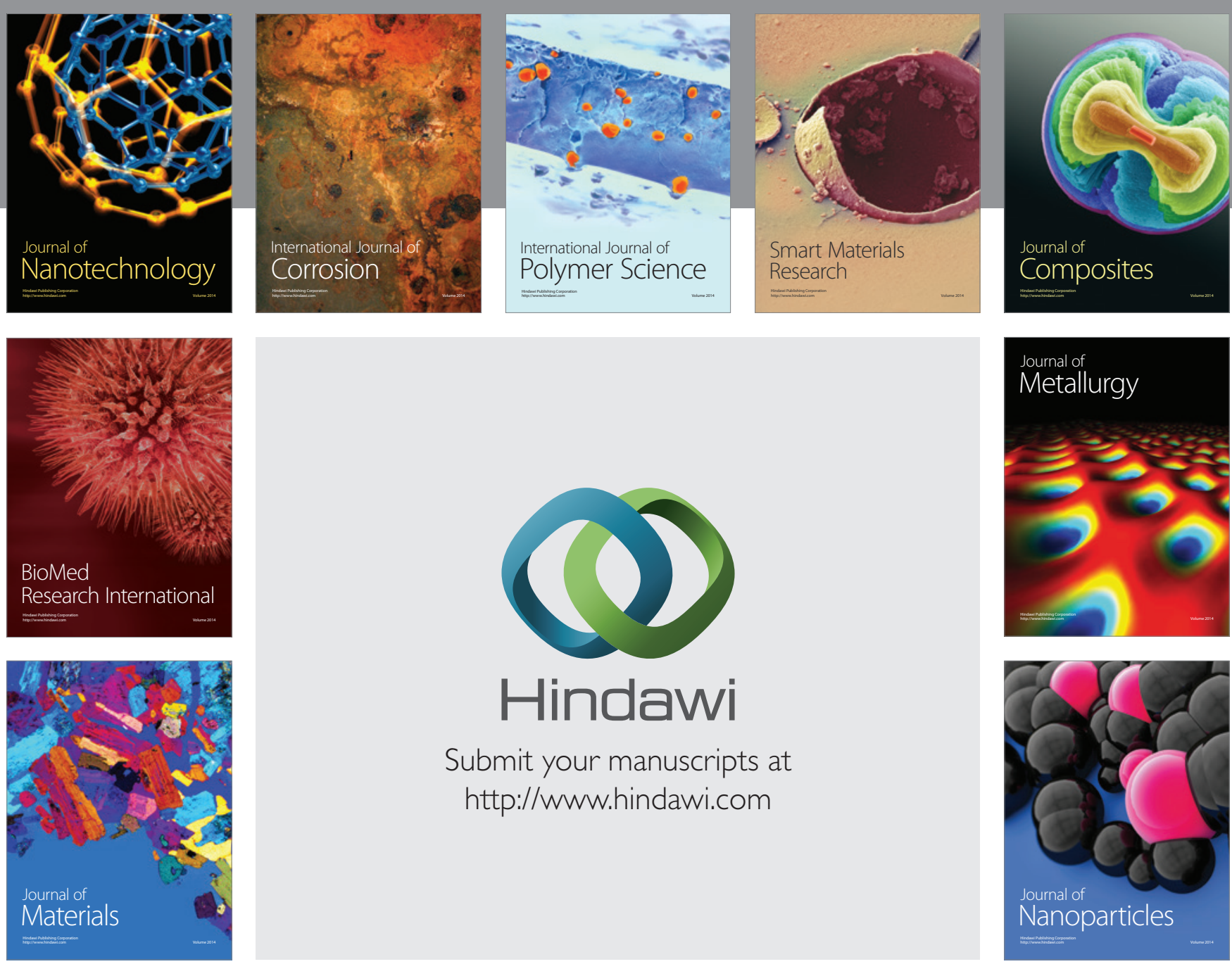

Submit your manuscripts at http://www.hindawi.com
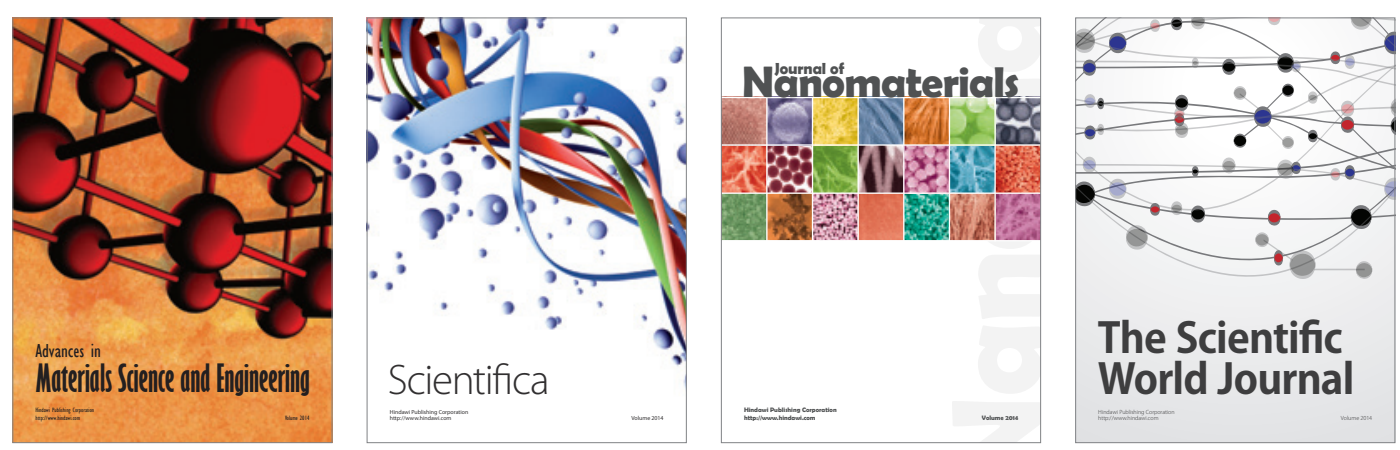

\section{The Scientific World Journal}
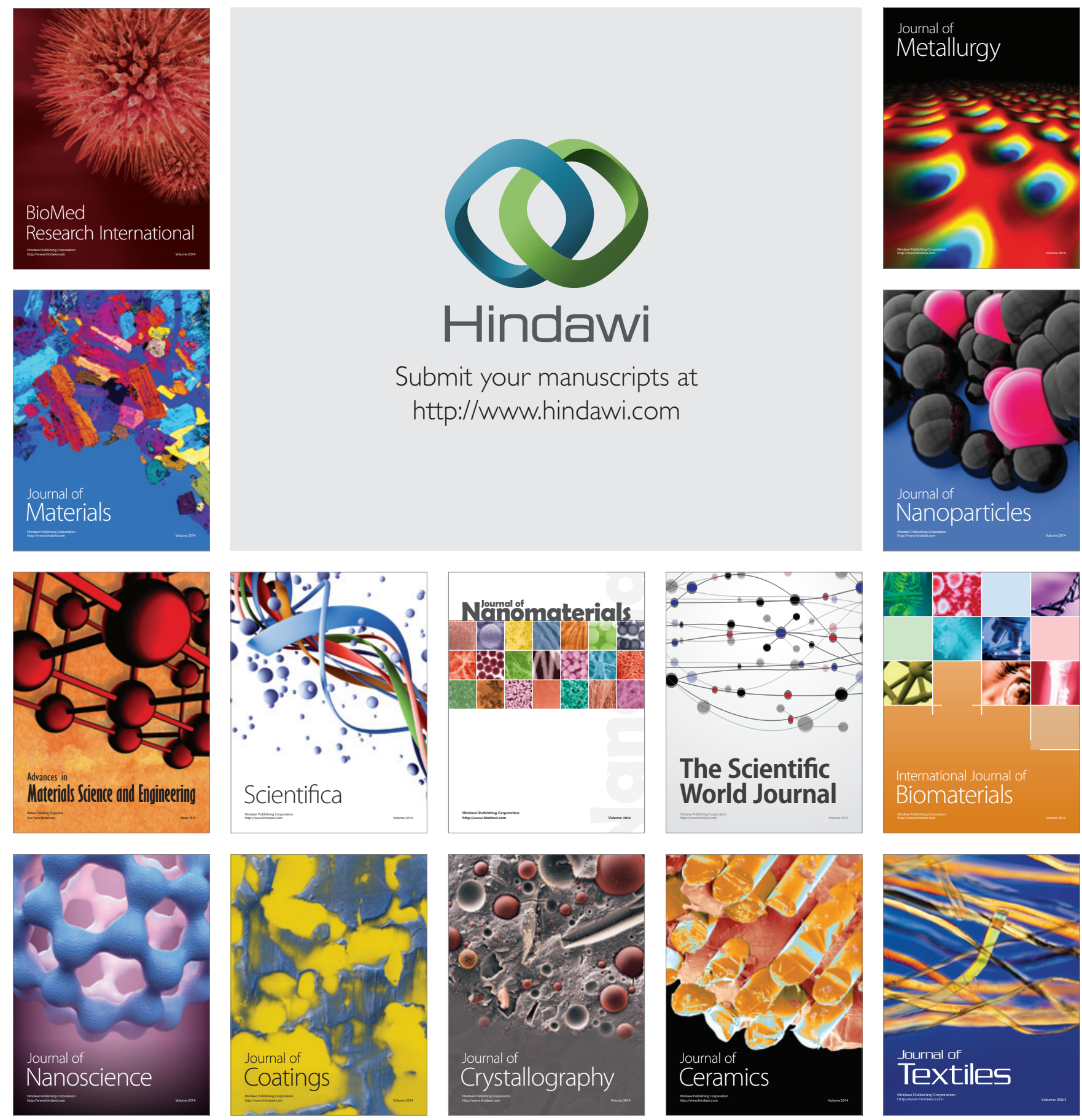